\title{
Conceptualizing the Environment in Natural Sciences: Guest Editorial
}

\author{
Gaëlle Pontarotti ${ }^{1} \cdot$ Antoine C. Dussault ${ }^{1,2}$ (D) . Francesca Merlin ${ }^{1}$
}

Accepted: 29 November 2021 / Published online: 6 January 2022

(c) Konrad Lorenz Institute for Evolution and Cognition Research 2022, corrected publication 2022

"Environment" is a pervasive and key concept in many disciplines, especially in the life sciences. In various biology subfields, "environment" appears to be an important theoretical tool used by scientists addressing diversified questions. In molecular and developmental biology, for instance, interactions between genes and environment are at the center of the investigation. Here, the environment appears as a causal entity that participates in ontogenesis through its incidence on the differential expression of genes. In evolutionary biology, natural populations are said to face the selective pressures of their environment, and in turn, to have an influence on the selective environment that acts upon them. A further example can be found in epidemiology, where the environment can refer to an internal or an external context influencing the health of human populations.

The concept of environment thus seems to have become the unifying theme of multifarious scientific discourses. At first glance, one could think that these discourses deal with the same object, raise similar problems, and work out solutions that are convergent or, at least to some degree, relevant across disciplines. However, it remains unclear what exactly is common to questions raised in the various fields dealing with the environment. What is common, for instance, to questions about the mutual influence of organisms and their environments, about selective pressure acting on populations, and about community assembly and/or ecosystem functioning? Can "environment" stand as an unequivocal and unified concept that can unproblematically be applied

Gaëlle Pontarotti

pontarottigaelle@gmail.com

Antoine C. Dussault

antoine.cdussault@clg.qc.ca

Francesca Merlin

francesca.merlin@univ-paris1.fr

1 IHPST - CNRS \& Université Paris 1 Panthéon-Sorbonne, Paris, France

2 Collège Lionel-Groulx/Centre interuniversitaire de recherche sur la science et la technologie (CIRST), Montréal, QC, Canada in any relevant discipline? Can the concept of environment used in one field be fruitfully transferred to another one with no particular epistemological precaution? Can it simply refer, in all its contexts of use, to what "surrounds" a focal entity? Are the "environments" invoked in different disciplines commensurable? If not, then an analysis of the concept(s) of environment involved in biological sciences seems called for.

Such considerations were the initial motivation for an exploratory workshop held in Paris on June 25 and 26, 2018. The aim of the workshop - which was titled "Conceptualizing the Environment in Natural Sciences" - was to launch a transdisciplinary discussion on the concept(s) of environment, to clarify its(their) use(s) in various biology subfields, to organize its(their) multiple meanings, and to identify these meanings' common grounds and divergences. Another purpose of the meeting was to better understand the role of the environment in contrasting disciplinary logics, for instance as an external explanatory factor (in the fields belonging to evolutionary and developmental biology) versus as an object of investigation per se (in ecology). The workshop also incorporated a historical analysis, aimed at highlighting how the concept of environment became prominent in the life sciences and how its meanings and/or focuses have evolved.

The present thematic issue is derived from that workshop. It includes papers dealing with the concept of environment as it is used in various contemporary biological subfields, as well as in the history of biology. In this respect, it is meant to complement previous edited volumes (Kabasenche et al. 2012; Barker et al. 2014) and independently published papers (e.g., Brandon 1990; Abrams 2009; Malmstrom 2010; Millstein 2014) addressing the notion. Its goal is more precisely to favor exchange between specialists of biology subdisciplines susceptible to having different takes on the concept of environment, in order to better appreciate its fuzziness and heterogeneity, and to explore whether and how an analysis that is more consistent across biological subfields might be developed. 
The volume explores the relationships between the concept of environment and similar notions such as habitat, niche, milieu, circumstance, Umwelt. Do these relationships vary within and across biological subfields? How do understandings of the niche in various biological areas (e.g., ecology, evolutionary biology, developmental biology) relate to each other and, for instance, to the concept of habitat? The special issue also questions the links between the concept of environment and key theoretical notions such as adaptation and inheritance. To what extent is the environment part of the definition of such notions? How does it participate in shaping the biological phenomena that they designate? The issue further asks whether "environment" in a biologically relevant sense is equivalent to the geographical environment. Finally, it addresses various crosswise problems: What criteria should be adopted for delineating the boundaries between biological entities and their environments? How do these criteria vary according to contexts and scales of investigation? What does it mean for some organisms to be in "the same" environment? In what ways do organisms and environments shape each other?

The first two papers delve into the history of the concept of environment. In "The Rise of the 'Environment': Lamarckian Environmentalism Between Life Sciences and Social Philosophy," ${ }^{1}$ Ferhat Taylan examines the Lamarckian conception of the environment and argues that its cornerstone was the idea of a life-supporting function of physicochemical milieux. He further explores how famous philosophers and social scientists of the 19th century adopted Lamarckian environmentalism, and how they interpreted it. Finally, he analyzes how the diverse acceptations of Lamarckian environmentalism contributed to the shaping of the philosophical and biological concept of environment. In "The Darwinian Turn in the Understanding of Biological Environment,"2 Gustavo Caponi documents the shift accomplished by Charles Darwin, from a notion of environment focused on abiotic factors, to a notion emphasizing the importance of biotic factors, i.e., living beings with whom a living being interacts. Although Caponi recognizes that some biologists prior to Darwin (e.g., Lyell) had initiated this shift, he explains how it took on a special importance for Darwin, in being an exigency of his theory of natural selection.

The third paper, "Environmental Inheritance: Conceptual Ambiguities and Theoretical Issues,"3 by Gaëlle Pontarotti, questions the introduction of environment in biological legacies, in the context of studies about "extended inheritance." It clarifies the different meanings of "environmental

\footnotetext{
1 Taylan, this issue, https://doi.org/10.1007/s13752-020-00358-3.

2 Caponi, this issue, https://doi.org/10.1007/s13752-020-00344-9.

${ }^{3}$ Pontarotti, this issue, https://doi.org/10.1007/s13752-020-00348-5.
}

inheritance" and addresses some of their theoretical limitations (theoretical redundancy, theoretical inconsistency). The author notably argues for the necessity to distinguish two related but different research programs, focused on distinct theoretical objects: the first being dedicated to a finergrained theory of environment, the second to an extended theory of inheritance. She asserts that the phenomena placed under the general label of "environmental inheritance" should be studied either in the context of the first or of the second project.

The fourth paper, "Functionalism without Selectionism: Charles Elton's 'Functional' Niche and the Concept of Ecological Function," 4 by Antoine C. Dussault, turns to ecology and attempts to shed light on ecologist Charles Elton's so-called "functional" understanding of the niche. Locating Elton's niche within the broader context of his "functionalist-interactionist" picture of ecological communities, and taking into account his skepticism with regards to the idea of communities as units of selection, Dussault links Elton's niche to a nonselectionist understanding of how organisms may be thought to fulfill functions within ecological communities.

The next two papers deal with the concept of environment in evolutionary biology. In "Environment as Abstraction,"5 Denis Walsh criticizes the customary view of the evolutionary environment as wholly external to organisms, and as a discrete and autonomous cause of evolution. He argues that adaptations, rather than being responses to an external environment, are responses to affordances, and that the external environment is therefore not the cause of adaptations, but rather a heuristically useful abstraction at work in evolutionary models. In "Adapting to Environmental Heterogeneity: Selection and Radiation,"6 Hugh Desmond asks what it means to adapt to environmental "complexity" or environmental "uncertainty." This explanatory motif recurs across diverse adaptationist explanations, ranging from accounts of the adaptiveness of homeostasis or cognition to selective explanations for the emergence of multicellularity. Desmond analyzes different patterns of heterogeneity and proposes to distinguish between two different types of adaptation to heterogeneity: selection, involving well-defined patterns of change, and radiation, involving novel change.

Finally, the paper entitled "What Is It Like To Be an Environment? A Semantic and Epistemological Inquiry,"7 by Philippe Huneman, takes a more general perspective on the concept of environment, and asks whether it is suitable to the same kind of philosophical explication and analysis

\footnotetext{
${ }^{4}$ Dussault, this issue, https://doi.org/10.1007/s13752-020-00360-9.

5 Walsh, this issue, https://doi.org/10.1007/s13752-020-00367-2.

${ }^{6}$ Desmond, this issue, https://doi.org/10.1007/s13752-021-00373-y.

${ }^{7}$ Huneman, this issue, https://doi.org/10.1007/s13752-021-00390-x.
} 
as other biological concepts such as fitness, species, and population. Huneman surveys and organizes various uses of "environment" in different fields (population genetics, niche construction theory, ecology, Gaïa hypothesis, etc.), and notably highlights that the concept is contrasted with different terms (genes, organisms, species, life, etc.). He finds that no common conceptual core can be identified regarding environment.

To conclude, the papers included in this issue, like the discussions held during the workshop, reveal the challenging dimension of a philosophical analysis dedicated to a concept that, while pervasive in biological (and other) discourses, is rarely put at center stage. The volume may therefore encourage further questioning in philosophy of biology, but also in other fields dealing with this so common but so thorny concept.

Acknowledgements This thematic Issue was supported by the ANR EnviroBioSoc Project (grant 19-CES26-0018-01 of the French Agence Nationale de la Recherche).

\section{References}

Abrams M (2009) What determines fitness? The problem of the reference environment. Synthese 166(1):21-40

Barker G, Desjardins E, Pearce T (eds) (2014) Entangled life: organism and environment in the biological and social sciences. Springer, Dordrecht

Brandon RN (1990) Adaptation and environment. Princeton University Press, Princeton

Kabasenche WP, O'Rourke M, Slater MH (eds) (2012) The environment: philosophy, science, and ethics. MIT Press, Cambridge. https://www.jstor.org/stable/j.ctt5vjq5k

Malmstrom C (2010) Ecologists study the interactions of organisms and their environment. Nature Education Knowledge 3(10):88

Millstein R (2014) How the concept of 'population' resolves concepts of 'environment.' Philosophy of Science 81:741-755

Publisher's Note Springer Nature remains neutral with regard to jurisdictional claims in published maps and institutional affiliations. 